Article

\title{
Comparative Proteomic Analysis Reveals Immune Competence in Hemolymph of Bombyx mori Pupa Parasitized by Silkworm Maggot Exorista sorbillans
}

\author{
Ping-Zhen $\mathrm{Xu}{ }^{1,2,+, *}$, Mei-Rong Zhang ${ }^{1,2,+}$, Li Gao ${ }^{1}$, Yang-Chun $\mathrm{Wu}^{1,2}$, He-Ying Qian ${ }^{1,2}$, \\ Gang $\mathrm{Li}^{1,2}$ and An-Ying $\mathrm{Xu}{ }^{1,2, *}$ \\ 1 School of Biotechnology, Jiangsu University of Science and Technology, Sibaidu Rd, \\ Zhenjiang 212018, China; zmr198254@163.com (M.-R.Z.); gaol910@163.com (L.G.); \\ jkdwyc@163.com (Y.-C.W.); qianheying123@163.com (H.-Y.Q.); sdlig-1@163.com (G.L.) \\ 2 Sericulture Research Institute, Chinese Academy of Agricultural Sciences, Sibaidu Rd, \\ Zhenjiang 212018, China \\ * Correspondence: xpz198249@163.com (P.-Z.X.); srixay@126.com (A.-Y.X.) \\ + These authors contributed equally to this work reported in this paper.
}

Received: 3 October 2019; Accepted: 15 November 2019; Published: 18 November 2019

\begin{abstract}
The silkworm maggot, Exorista sorbillans, is a well-known larval endoparasitoid of the silkworm Bombyx mori that causes considerable damage to the silkworm cocoon crop. To gain insights into the response mechanism of the silkworm at the protein level, we applied a comparative proteomic approach to investigate proteomic differences in the hemolymph of the female silkworm pupae parasitized by E. sorbillans. In total, 50 differentially expressed proteins (DEPs) were successfully identified, of which 36 proteins were upregulated and 14 proteins were downregulated in response to parasitoid infection. These proteins are mainly involved in disease, energy metabolism, signaling pathways, and amino acid metabolism. Eight innate immune proteins were distinctly upregulated to resist maggot parasitism. Apoptosis-related proteins of cathepsin B and 14-3-3 zeta were significantly downregulated in E. sorbillans-parasitized silkworm pupae; their downregulation induces apoptosis. Quantitative PCR was used to further verify gene transcription of five DEPs, and the results are consistent at the transcriptional and proteomic levels. This was the first report on identification of possible proteins from the E. bombycis-parasitized silkworms at the late stage of parasitism, which contributes to furthering our understanding of the response mechanism of silkworms to parasitism and dipteran parasitoid biology.
\end{abstract}

Keywords: Bombyx mori; Exorista sorbillans; parasitoid; proteomics; two-dimensional gel electrophoresis

\section{Introduction}

To combat microbial infection and eukaryotic parasite infestation, insects have efficient and potent innate immune systems [1-6]. Infection and infestation activate defense mechanisms, including cellular and humoral immune responses. Exogenous invaders are first recognized by recognition factors to trigger cellular immune reactions and humoral immune reactions [2,4]. After the recognition procedure, modulating and signaling factors are next activated [2]. Signaling transduction is stimulated in major immune tissues, such as the fat body and hemocytes, and the gene encoding effectors are activated through signaling cascades [2,4]. The effector molecules are produced in specific tissues and secreted into the hemolymph [2].

The domesticated silkworm originated in China, has been distributed to different parts of the world [7], and is an economically important animal. The silkworm maggot Exorista sorbillans, a well-known larval endoparasitoid of the silkworm, is found in all silk producing areas of Asia, severely 
damaging the silkworm cocoon crop [8,9]. The mated gravid female E. sorbillans oviposit on the epidermis of a silkworm larva. After about 48 hours, the parasitic maggots hatch and invade the Bombyx mori larvae. In silkworms, immune reactions are triggered after infestation by Exorista bombycis $[2,8,9]$. The expression of immune proteins and the encoding genes are enhanced in the epithelium of E. bombycis-infested silkworm larvae. In hemocytes of the host $B$. mori larva after infestation by the parasitoid larva of E. bombycis, the level of reactive oxygen species (ROS) as measured by $\mathrm{H}_{2} \mathrm{O}_{2}$ production increases from six hours and continues to increase, significantly reaching maximum at $48 \mathrm{~h}$; the $\mathrm{H}_{2} \mathrm{O}_{2}$ production causes cytotoxicity, lipid peroxidation, and membrane porosity that suppress both the humoral- and cell-mediated immune responses of hemocytes in B. mori [10]. In the early stage of parasitization, the antioxidative enzyme levels are maintained at a high level in silkworm hemocytes, revealing the continuous need for antioxidative enzymes to prevent immune suppression by enduring parasitism in the host [11]. Under parasitic influence, the expressions of cell apoptosis-associated genes, including autophagy 5-like (Atg5), apoptosis-inducing factor (AIF), and nedd2-like caspase, are enhanced in the larval integument of $B$. mori [12], which indicates parasitism-induced activation of apoptosis in the host $[8,9]$.

At a stable temperature of $25^{\circ} \mathrm{C}$, the eggs of silkworm maggot, E. sorbillans are incubated for about two days before hatching, after which the newly hatched first instar parasitoid larvae invade the host B. mori cuticle. Maggots invade the silkworm body and parasitize between the body wall and muscle, which is identified by the presence of black markings on the epidermis at the point of infection [9]. The parasitoid maggot completes larval stages inside the silkworm fifth instar larvae for about five days [9]. Some molecular mechanisms of the early stage of parasitization have been reported previously, but the mechanism during the late stage is not yet clear. Otherwise, during silkworm larval-pupal metamorphosis, degradation of tissues that are no longer needed is an essential process [13]. B. mori undergo distinct morphological changes; the 9th and 12th ventral segments of larva are healed in pupa, which may impact maggot parasitism.

In this study, we used two-dimensional gel electrophoresis (2-DE) combined with mass spectrometry (MS) to explore the differences in hemolymph protein expression in the day- 1 female silkworm pupae parasitized by E. sorbillans. This is the late stage and the third (final) instar larva of the endoparasitic maggot. Then, the third instar maggot was elicited from the silkworm body and pupated outside. We successfully identified 50 differentially expressed proteins (DEPs), obtained protein information, and annotated the molecular function. Our study provides an overview of the proteomic profile in the hemolymph of $B$. mori response to E. sorbillans parasitic infection and lays a foundation for clarifying the mechanism of silkworm resistance to E. sorbillans.

\section{Materials and Methods}

\subsection{Experimental Animals and Sample Preparation}

Larvae of the B. mori strain Baiyu were reared on mulberry leaves at a stable temperature of $25^{\circ} \mathrm{C}$. The day-2 fifth instar larvae were exposed to mated gravid females of $E$. sorbillans for oviposition for 3 hours. Only one egg was allowed on the larval surface of each host through physical removal of other eggs if any were present. Control larvae were maintained without infestation. The infected and control silkworm larvae were fed until the silkworm matured to avoid the effect of starvation. The larvae, larvae-pupae, and pupae were maintained under a 12-h light/dark photoperiod at $25^{\circ} \mathrm{C}$ and $70 \%$ humidity. Hemolymph, hemocytes, and the fat body were collected from the infected and control female silkworm pupae on the first day of pupation. This time is the late stage and the third (final) instar larva of the endoparasitic maggot. Then, the third instar maggot was obtained from the silkworm body and pupated outside. The hemolymph samples were centrifuged for 10 minutes at $12,000 \mathrm{rpm}$ at $4{ }^{\circ} \mathrm{C}$ and stored in a lysis buffer of $9 \mathrm{M}$ urea, $4 \%$ the zwitterionic 3-[(3-cholamidopropyl) dimethylamino]-1-propanesulfonate (CHAPS), $1 \%$ dithiothreitol, $1 \%$ immobilized $\mathrm{pH}$ gradient (IPG) buffer, and a $1 \%$ protease inhibitor cocktail. The total protein content was quantified using a Bradford 
assay kit (Bio-Rad, Hercules, CA, USA). The hemolymph is an open circulatory system. The major proteins in the hemolymph are produced in other specific tissues and secreted into the hemolymph, and the fat body is the one of the specific tissues [14]. Thus, the hemocytes and fat body samples were used to verify gene expressional analysis.

\subsection{2-DE and Protein Digestion}

The proteins were separated with 2-DE. In short, $200 \mu \mathrm{g}$ of each sample protein was added to a 24-cm broad range IPG strip (nonlinear, $\mathrm{pH} 3$ to 10) for isoelectric focusing (IEF), and 2-DE was performed in $12.5 \%$ polyacrylamide gel. The gel was stained with silver nitrate following the 2-DE procedure [15]. Spots were scanned at $300 \mathrm{dpi}$ using a high-resolution image scanner and analyzed using PDQuest 8.0 software (Bio-Rad, Hercules, CA, USA). For statistical analysis of the data, we used a Student's $t$-test and the fold ratio was calculated. Three replicates were performed, and a threshold of $p \leq 0.05$ and fold changes of $\geq 2.5$ or $\leq 0.4$ were used to identify differently expressed protein spots. The marked protein spots were identified. Differentially expressed protein spots were cut from the gel with a scalpel and washed twice with ultrapure water. The samples were destained for $5 \mathrm{~min}$, the destaining solution was removed, and the samples were washed twice and incubated in $50 \%$ acetonitrile for $5 \mathrm{~min}$, removing the acetonitrile with the addition of 100\% acetonitrile for $5 \mathrm{~min}$. Each sample was rehydrated in $4.0 \mu \mathrm{L}$ of trypsin solution (Promega, Madison, WI, USA) for $30 \mathrm{~min}$, and we added $16 \mu \mathrm{L}$ of cover solution. After digestion at $37^{\circ} \mathrm{C}$ for $16 \mathrm{~h}$, the supernatant was transferred into a new tube and extracted once with $50 \mu \mathrm{L}$ extraction buffer $(67 \%$ acetonitrile and $5 \%$ trifluoroacetic acid). The combined extraction solution was completely dried. The dried peptides were dissolved in $5 \mu \mathrm{L} 0.1 \%$ trifluoroacetic acid (TFA) and then mixed in a 1:1 ratio with a saturated solution of $\alpha$-cyano-4-hydroxycinnamic acid in 50\% acetonitrile containing $0.1 \%$ TFA.

\subsection{MALDI-TOF/TOF-MS/MS Analysis and Protein Identification}

The mass spectrometry (MS) spectra of digested peptides were performed on 5800 MALDI-TOF/TOF Plus mass spectrometer (Applied Biosystems, Foster City, CA, USA). The data were obtained in a positive MS reflector using a CalMix 5 standard to adjust by an I 5800 TOF-TOF Proteomics Analyser (Applied Biosystems, Framingham, MA, USA). The databases used in this analysis were obtained from NCBI (http://www.ncbi.nlm.nih.gov; 6391 sequences) and SilkDB (http://www.silkdb.org/silkdb; 20361 sequences). The analysis of both the MS and MS/MS spectra data and the protein identification processes were implemented in accordance with a previous study [16]. The peptides of the quantified proteins were provided in Table S1. Gene Ontology (GO) assignments were completed using Blast2GO (https://www.blast2go.com/) and obtained corresponding GO identification numbers (IDs) of the identified proteins using InterproScan 5.0 sequence search [17,18]. GO annotation results of the DEPs were provided in Table S2. The Kyoto Encyclopedia of Genes and Genomes (KEGG) was used to perform pathway enrichment analysis of the identified proteins [19]. Descriptions of the KEGG pathways were provided in Table S3.

\subsection{Quantitative PCR}

The genes selected according to the DEPs were investigated by quantitative PCR (qPCR) at the transcriptional level. Total RNA from the hemocytes and fat body of the infected and control samples was used to synthesize the first strand cDNA using a PrimeScript Reverse Transcriptase kit (TaKaRa, Dalian, China) according to the manufacturer's instructions. Specific primers of genes for qPCR are listed in Table S4. qPCR was performed as previously described [20]. The gene expression levels were calculated using the $2^{-\Delta \Delta \mathrm{Ct}}$ method. There were three biological sample replicates, and each biological sample replicate included three independent experiments. The reference gene was $B$. mori ribosomal protein gene BmRPL3. The statistical analysis was conducted using ANOVA, followed by an LSD a posteriori test via SPSS statistical software (version 16.0; SPSS, Inc., Chicago, IL, USA). 


\section{Results}

\subsection{Identification of DEPS}

In the interest of understanding the molecular mechanism of the late stage of E. sorbillans-parasitized silkworms at the protein level, we collected the hemolymph of female silkworm pupae on the first day of pupation and conducted 2-DE combined with MALDI-TOF/TOF-MS/MS analysis to identify the DEPs. The protein molecular mass varied within a normal range of approximately 10 to $116 \mathrm{kDa}$, and isoelectric point ( $\mathrm{pI}$ ) values ranged from 3 to 10 (Figure 1, Table S1), suggesting that protein extraction was correctly performed and that most proteins from the hemolymph were obtained. A differentially expressed spot was defined as a spot with a 2.5-fold or greater change in intensity and frequency higher than 40\%. According to the criteria, 36 upregulated and 14 downregulated spots were selected and subjected to MS/MS identification (Table 1). The DEPs ranged from 10 to $82 \mathrm{kDa}$ in molecular mass and from pH 4 to 10 in pI. Detailed information, including the spot numbers, accession numbers, predicted molecular weights (MWs), pIs, sequence coverage, peptide count, fold change, and signal peptide, is provided in Table 1. The following eight innate immune proteins were upregulated in the infected group: PPO2 (spot 1), paralytic peptide binding protein (spot 4), antitrypsin (spot 6), CTL10 (spot 10), apolipophorin III (spot 22), translationally controlled tumor protein (spot 23), peptidoglycan recognition protein (spot 27), and ubiquitin-like protein SMT3 (spot 36) (Figure 1 and Table 1). Apoptosis-related proteins of cathepsin B (spot 43) and 14-3-3 zeta (spot 45) were significantly downregulated in the infected group (Figure 1 and Table 1). In this study, we analyzed the tissue expression patterns of the genes encoding the DEPs based on the microarray data. The raw data of 10 silkworm tissues on day 3 of the fifth instar were obtained from SilkMDB. We found many highly expressed genes in the epidermis amongst the 10 tissues (Figure S1). The expressed genes are defined as previously described [21]. This finding may be closely related to the epidermal invasion of maggots in the silkworm. Our data contribute to the understanding of the infection pathway of maggots.
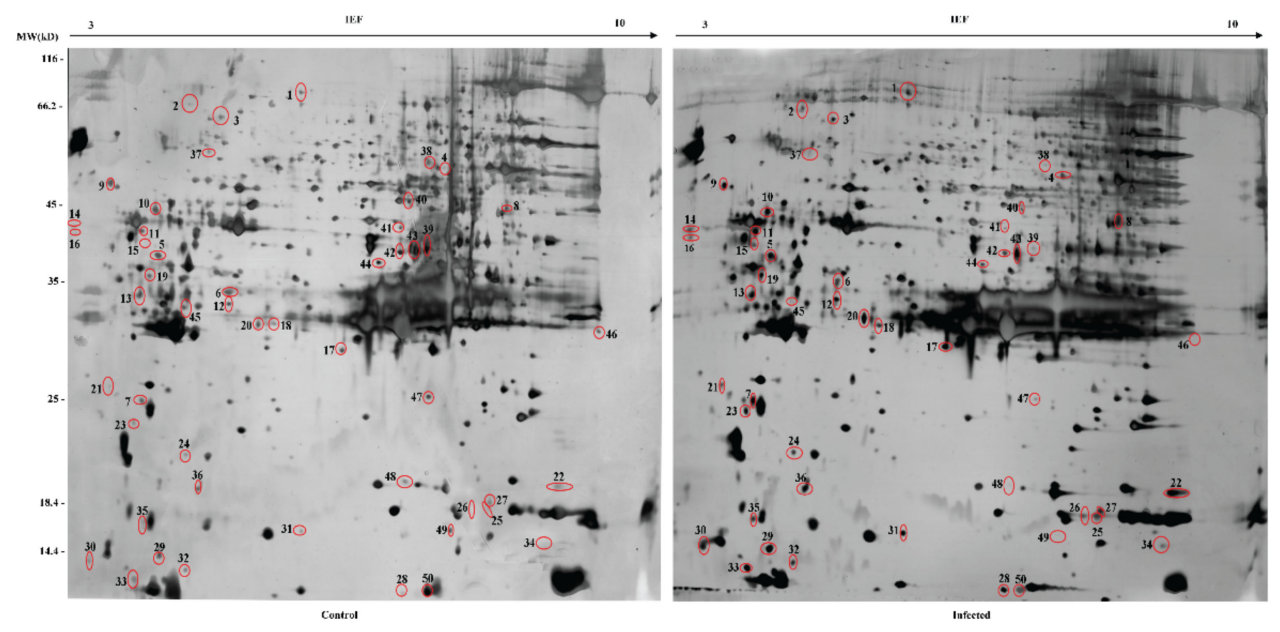

Figure 1. Two-dimensional gel electrophoresis (2-DE) maps of the control and infected hemolymph collected from day-1 female silkworm pupae: The differentially expressed proteins (DEPs) are indicated by circles and numeric labels, which correspond to the numbers presented in Table 1. All samples were processed in parallel. 
Table 1. Data of the 50 DEPs identified by MALDI-TOF/TOF-MS/MS.

\begin{tabular}{|c|c|c|c|c|c|c|c|c|c|}
\hline Spot No. & Protein Name & SilkDB Accession No. & $\begin{array}{c}\text { NCBI } \\
\text { Accession No. }\end{array}$ & $\begin{array}{c}\text { Theoretical } \\
\text { (kDa/pI) }\end{array}$ & $\begin{array}{c}\text { Sequence } \\
\text { Coverage(\%) }\end{array}$ & $\begin{array}{c}\text { Peptides } \\
\text { Identified }\end{array}$ & $\begin{array}{c}\text { Fold } \\
\text { Change } \\
\end{array}$ & $\begin{array}{l}\text { Signal } \\
\text { Peptide }\end{array}$ & Function \\
\hline \multicolumn{10}{|l|}{ Upregulated } \\
\hline 1 & phenoloxidase subunit 2 precursor & BGIBMGA013115-PA & gi|112983448 & $80.12 / 5.62$ & 18 & 11 & 3.66 & - & Serine protease involved in melanization \\
\hline 2 & $\begin{array}{l}\text { very low-density lipoprotein receptor } \\
\text { isoform } 1 \text { precursor }\end{array}$ & BGIBMGA006214-PA & gi|160333138 & $61.54 / 5.20$ & 4 & 3 & 4.53 & - & Chitin metabolic \\
\hline 3 & $\begin{array}{l}60 \mathrm{kDa} \text { heat shock protein, } \\
\text { mitochondrial-like }\end{array}$ & BGIBMGA007349-PA & gi|512896628 & $61.06 / 5.51$ & 22 & 8 & 2.61 & - & Protein refolding \\
\hline 4 & paralytic peptide binding protein & BGIBMGA010168-PA & gi|112983896 & $50.01 / 6.33$ & 30 & 11 & 3.17 & - & Extracellular region \\
\hline 5 & uncharacterized protein LOC101739845 & BGIBMGA002604-PA & gi|512931715 & $49.40 / 5.42$ & 15 & 6 & 2.94 & - & Farnesoic acid o-methyltransferase \\
\hline 6 & antitrypsin & BGIBMGA009953-PA & gi|253809709 & $43.43 / 5.41$ & 26 & 8 & 9.88 & - & Peptidase inhibitor activity \\
\hline 7 & failed axon connections isoform X1 & BGIBMGA000552-PA & gi|512921311 & $42.89 / 5.31$ & 11 & 3 & 3.64 & - & $\mathrm{N} / \mathrm{A}$ \\
\hline 8 & proliferation-associated protein $2 \mathrm{G} 4$ & BGIBMGA002493-PA & gi|512926720 & $42.14 / 7.13$ & 33 & 9 & 3.24 & - & Cellular process \\
\hline 9 & DNA supercoiling factor & BGIBMGA001107-PA & gi|347326520 & $38.02 / 4.48$ & 40 & 12 & 2.83 & - & Calcium ion binding \\
\hline 10 & C-type lectin 10 & BGIBMGA006768-PA & gi|148298818 & $36.56 / 5.53$ & 6 & 2 & 3.59 & & Carbohydrate binding \\
\hline 11 & $32 \mathrm{kDa}$ apolipoprotein precursor & BGIBMGA002703-PA & gi|226501956 & $32.09 / 4.79$ & 7 & 3 & 2.91 & 1 & Pigment binding \\
\hline 12 & spermidine synthase & BGIBMGA005897-PA & gi|512899761 & $32.43 / 5.54$ & 26 & 8 & 3.15 & - & Catalytic activity \\
\hline 13 & $\begin{array}{l}\text { small glutamine-rich tetratricopeptide } \\
\text { repeat-containing protein alpha-like }\end{array}$ & BGIBMGA010000-PA & gi|827549620 & $31.43 / 4.88$ & 8 & 2 & 5.77 & - & Protein binding \\
\hline 14 & $\begin{array}{l}\text { uncharacterized protein LOC778506 } \\
\text { isoform X1 }\end{array}$ & - & gi|827559778 & $30.66 / 4.31$ & 9 & 2 & 4.22 & - & Cell surface glycoprotein \\
\hline 15 & gasp precursor & BGIBMGA007677-PA & gi|114052326 & 29.09/4.82 & 7 & 1 & 24.35 & 1 & Chitin binding \\
\hline 16 & $\begin{array}{l}\text { uncharacterized protein LOC778506 } \\
\text { isoform X2 }\end{array}$ & - & gi|827559780 & $28.45 / 4.25$ & 9 & 2 & 4.15 & 1 & N/A \\
\hline 17 & $\begin{array}{l}\text { low molecular mass } 30 \mathrm{kDa} \text { lipoprotein } \\
21 \mathrm{G} 1 \text { isoform X1 }\end{array}$ & BGIBMGA004395-PA & gi|827538310 & $30.24 / 6.84$ & 33 & 9 & 5.78 & 1 & Extracellular region \\
\hline 18 & $\begin{array}{l}\text { low molecular } 30 \mathrm{kDa} \text { lipoprotein } \\
\text { PBMHPC-19-like precursor }\end{array}$ & BGIBMGA004398-PA & gi|525343846 & $28.50 / 5.72$ & 13 & 3 & 5.77 & 1 & Extracellular region \\
\hline 19 & charged multivesicular body protein 5 & BGIBMGA002470-PA & gi|512926615 & $25.26 / 4.71$ & 16 & 2 & 4.34 & - & Protein transport \\
\hline 20 & Rab7 & BGIBMGA007712-PA & gi|114051368 & $23.42 / 5.16$ & 4 & 1 & 8.85 & - & $\begin{array}{l}\text { Small GTPase mediated signal } \\
\text { transduction }\end{array}$ \\
\hline 21 & uncharacterized protein LOC101746349 & BGIBMGA006731-PA & gi|512923633 & 20.06/4.56 & 27 & 4 & 5.38 & 1 & N/A \\
\hline 22 & apolipophorin III & BGIBMGA013108-PA & gi|112983018 & $20.73 / 9.04$ & 29 & 7 & 7.04 & 1 & Defense response \\
\hline 23 & translationallycontrolled tumor protein & BGIBMGA003073-PA & gi|112982880 & 19.86/4.66 & 13 & 2 & 31.59 & - & Pathogen binding \\
\hline 24 & translation initiation factor $5 \mathrm{~A}$ & BGIBMGA007469-PA & gi|112982832 & $17.52 / 5.16$ & 14 & 2 & 2.93 & - & Translational frameshifting \\
\hline 25 & abnormal wing disc-like protein & BGIBMGA007701-PA & gi|153791847 & $17.31 / 6.74$ & 26 & 5 & 11.04 & - & Nucleoside diphosphate phosphorylation \\
\hline 26 & cyclophilin-like protein & BGIBMGA002429-PA & gi|60592747 & 17.96/7.74 & 17 & 2 & 3.81 & - & Protein peptidyl-prolyl isomerization \\
\hline 27 & peptidoglycan recognition protein & BGIBMGA008038-PA & gi|112983994 & $21.63 / 6.70$ & 33 & 6 & 3.32 & 1 & $\begin{array}{l}\mathrm{N} \text {-acetylmuramoyl-L-alanine amidase } \\
\text { activity }\end{array}$ \\
\hline 28 & $\begin{array}{l}\text { probable pterin-4-alpha-carbinolamine } \\
\text { dehydratase }\end{array}$ & - & gi|512899129 & $17.93 / 9.94$ & 30 & 3 & 18.51 & - & $\begin{array}{l}\text { 4- } \alpha \text {-hydroxytetrahydrobiopterin } \\
\text { dehydratase activity }\end{array}$ \\
\hline 29 & odorant-binding protein 6 isoform X1 & BGIBMGA008354-PA & gi|827551076 & $15.96 / 4.94$ & 18 & 3 & 3.41 & 1 & Odorant binding \\
\hline 30 & E3 ubiquitin-protein ligase ZNRF2 & BGIBMGA011980-PA & gi|512897556 & $21.91 / 5.42$ & 7 & 1 & 4.56 & - & Zinc ion binding \\
\hline 31 & ribosomal protein S12 & BGIBMGA004374-PA & gi|112982671 & $15.03 / 5.79$ & 24 & 2 & 4.62 & - & Structural constituent of ribosome \\
\hline 32 & chemosensory protein 4 precursor & BGIBMGA004045-PA & gi|112983094 & $14.55 / 5.17$ & 8 & 1 & 2.51 & 1 & $\begin{array}{l}\text { Transporters of pheromone/odor } \\
\text { molecules }\end{array}$ \\
\hline 33 & chemosensory protein 7 precursor & BGIBMGA004041-PA & gi|112983052 & $13.52 / 4.97$ & 18 & 3 & 4.77 & - & $\begin{array}{l}\text { Transporters of pheromone/odor } \\
\text { molecules }\end{array}$ \\
\hline 34 & FK506-binding protein & BGIBMGA004331-PA & gi|114051243 & $11.82 / 7.85$ & 43 & 4 & 10.66 & - & Isomerase activity \\
\hline 35 & $\begin{array}{l}\text { uncharacterized protein LOC101736984 } \\
\text { isoform X3 }\end{array}$ & BGIBMGA007627-PA & gi|512916631 & $11.18 / 5.02$ & 9 & 1 & 3.53 & - & $\mathrm{N} / \mathrm{A}$ \\
\hline 36 & ubiquitin-like protein SMT3 & BGIBMGA011581-PA & gi|112983974 & $10.31 / 5.29$ & 23 & 3 & 2.73 & - & Protein binding \\
\hline
\end{tabular}


Table 1. Cont.

\begin{tabular}{|c|c|c|c|c|c|c|c|c|c|}
\hline Spot No. & Protein Name & SilkDB Accession No. & $\begin{array}{c}\text { NCBI } \\
\text { Accession No. }\end{array}$ & $\begin{array}{c}\text { Theoretical } \\
(\mathrm{kDa} / \mathrm{pl})\end{array}$ & $\begin{array}{c}\text { Sequence } \\
\text { Coverage }(\%)\end{array}$ & $\begin{array}{c}\text { Peptides } \\
\text { Identified }\end{array}$ & $\begin{array}{c}\text { Fold } \\
\text { Change }\end{array}$ & $\begin{array}{c}\text { Signal } \\
\text { Peptide }\end{array}$ & Function \\
\hline \multicolumn{10}{|l|}{ Downregulated } \\
\hline 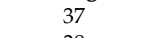 & heat shock protein 83 & BGIBMGA004612-PA & gi|112983556 & $82.42 / 4.98$ & 3 & 2 & 0.11 & - & Unfolded protein binding \\
\hline 38 & ATP synthase & BGIBMGA001853-PA & gi|114052278 & $59.66 / 9.21$ & 4 & 2 & 0.21 & - & ATP binding \\
\hline 39 & serine proteinase-like protein isoform X1 & BGIBMGA009551-PA & gi|827563139 & $44.88 / 5.73$ & 15 & 6 & 0.01 & 1 & Serine-type endopeptidase activity \\
\hline 40 & ornithine aminotransferase, mitochondrial & BGIBMGA003564-PA & gi|512922127 & $44.70 / 6.36$ & 5 & 2 & 0.21 & - & Pyridoxal phosphate binding \\
\hline 41 & aldose 1-epimerase & BGIBMGA009232-PA & gi|512891308 & $39.71 / 5.88$ & 27 & 7 & 0.28 & - & Transaminase activity \\
\hline 42 & aldo-ketoreductase AKR2E4-like isoform & BGIBMGA001348-PA & gi|512908850 & $38.99 / 5.82$ & 10 & 5 & 0.26 & 1 & Oxidoreductase activity \\
\hline 43 & cathepsin B & BGIBMGA007061-PA & gi 112983908 & $37.56 / 5.95$ & 18 & 5 & 0.17 & - & Regulation of catalytic activity \\
\hline 44 & aldose reductase-like isoform X1 & BGIBMGA012152-PA & gi|512901366 & $35.84 / 6.10$ & 20 & 6 & 0.39 & - & Oxidoreductase activity \\
\hline 45 & 14-3-3 protein zeta & BGIBMGA002644-PA & gi|114050901 & 28.17/4.90 & 6 & 2 & 0.21 & - & Protein domain specific binding \\
\hline 46 & vacuolar ATP synthase subunit E & BGIBMGA010247-PA & gi|114052088 & $26.12 / 8.98$ & 17 & 3 & 0.19 & - & ATP hydrolysis \\
\hline 47 & tyrosine-protein phosphatase Lar & BGIBMGA012106-PA & gi|512933991 & $22.75 / 6.29$ & 7 & 1 & 0.18 & 1 & Protein binding \\
\hline 48 & diapause bioclock protein & BGIBMGA002907-PA & gi|68144076 & $18.29 / 6.12$ & 27 & 3 & 0.15 & 1 & Superoxide dismutase activity \\
\hline 49 & ecdysteroid-regulated $16 \mathrm{kDa}$ protein & BGIBMGA008405-PA & gi|151301100 & $15.82 / 5.92$ & 12 & 1 & 0.01 & 1 & Ecdysteroid level regulated \\
\hline 50 & $\begin{array}{l}\text { precursor } \\
\text { chemosensory protein } 5 \text { precursor }\end{array}$ & BGIBMGA004065-PA & gi|112983054 & $14.26 / 6.89$ & 22 & 3 & 0.23 & 1 & RNA-binding \\
\hline
\end{tabular}

Note: - no signal peptide was predicted and no SilkDB accession number was found; N/A not applicable. 


\subsection{GO Annotation and KEGG Pathway Enrichment Analysis of the DEPS}

According to the GO annotation, 49 of the 50 identified DEPs were discovered with at least one GO match (Table S2). Based on the GO database, the identified DEPs were classified into three categories: cellular component, molecular function, and biological process (Figure 2). In the cellular component category, the DEPs are involved in different cellular processes and the extracellular region of the cell and macromolecular complex were the main members. The DEPs are mainly related to binding and catalysis in the molecular function category. The biological process category showed DEPs that are mainly involved in cellular, metabolic, and single-organism processes. KEGG pathway enrichment analysis of the identified DEPs showed that the main pathways are involved in disease, energy metabolism, signaling pathways, and amino acid metabolism (Table 2 and Table S3).

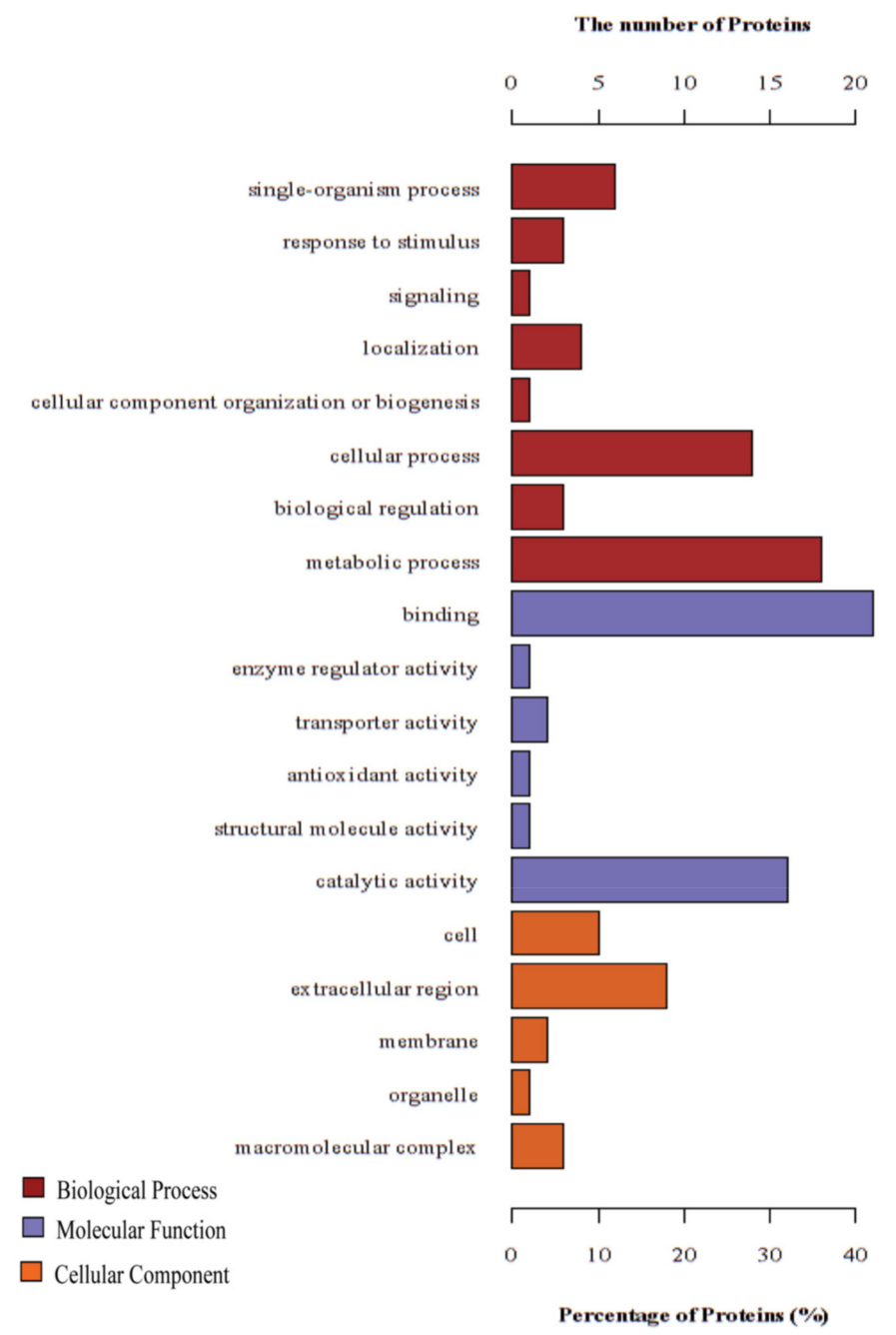

Figure 2. Distribution of the Gene Ontology (GO) terms for all proteins identified from the control and infected hemolymph: The DEPs were classified into cellular component, molecular function, and biological process by GO. 
Table 2. Kyoto Encyclopedia of Genes and Genomes (KEGG) pathway enrichment analysis of DEPs.

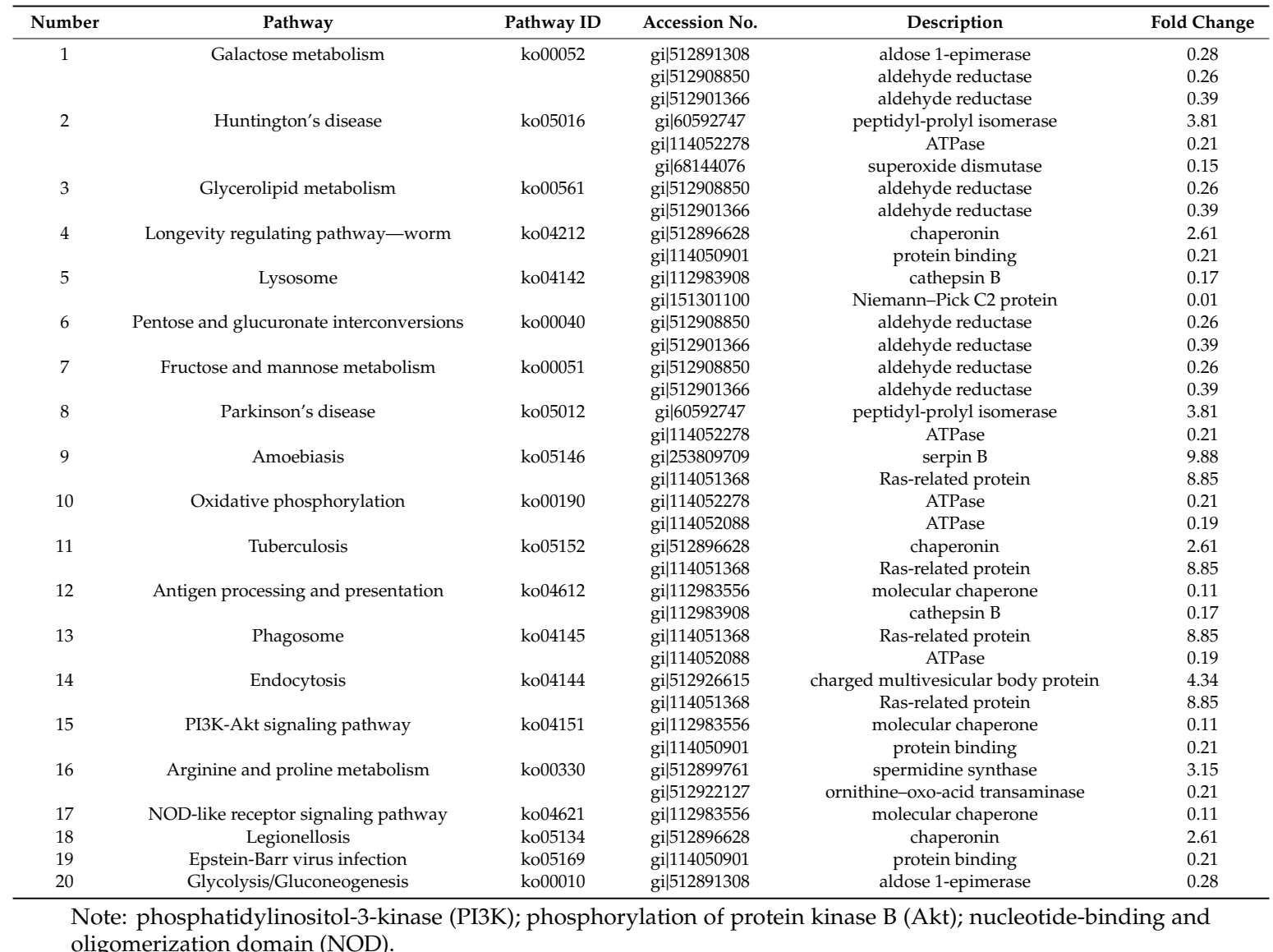

\subsection{Verification of Gene Expressions by Quantitative PCR}

To validate the 2-DE result, we also performed qPCR on some selected targets in the control and E. sorbillans-infected hemocytes and fat bodies. The insect hemolymph is an open circulatory system. During larval-pupal metamorphosis, the fat body maintains intracellular homeostasis and meets the requirements of metamorphosis. Thus, the fat body was also used to verify gene transcription of the DEPs in the hemolymph. The fat body and hemocytes were collected from day- 1 female silkworm pupae at the same time point. The information on the five selected differentially expressed genes and B. mori ribosomal protein gene BmRPL3 primers are presented in Table S4. In the hemocytes and fat body, the transcriptional expression levels of phenoloxidase subunit 2 precursor (PPO2), CTL10, and peptidoglycan recognition protein (PGRP-S1) were increased with infection, whereas the gene expression levels of ecdysteroid-regulated $16 \mathrm{kDa}$ protein (ESR16) and 14-3-3 protein zeta (14-3-3z) decreased with infection (Figure 3A,B). The induced fold-change of every gene was different, whereas the tendencies to expression changes were consistent between the hemocytes and fat body tissues. In summary, the changes in the gene transcription were consistent with their corresponding proteins in the 2-DE data. 

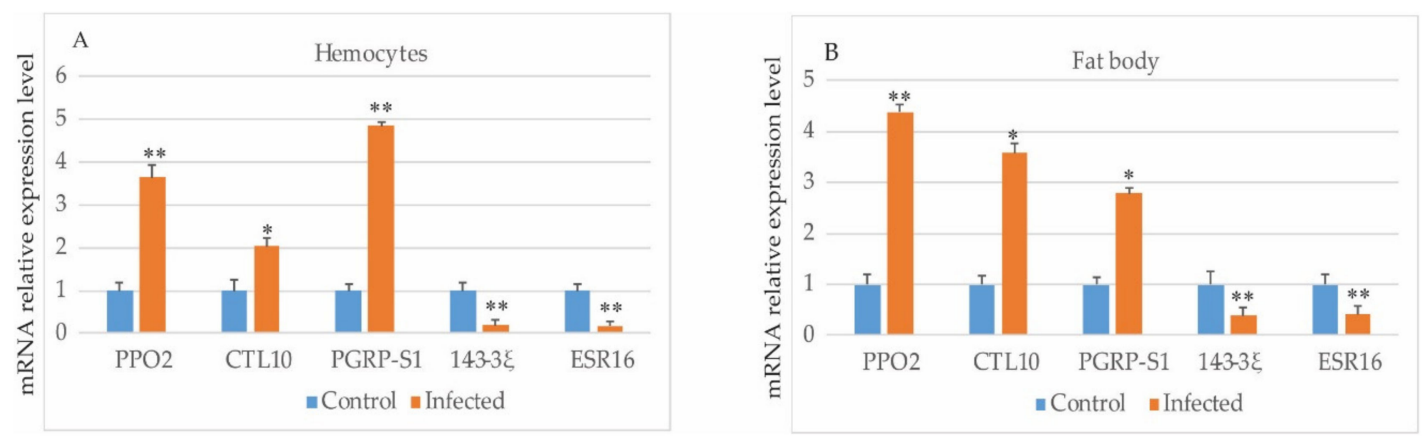

Figure 3. Expression profiles of five genes in the control and infected (A) hemocytes and (B) fat bodies collected from day-1 female silkworm pupae: For each gene, the transcriptional level of the control was set to 1 . The data are the means \pm SD of three independent experiments. Statistical analysis was performed using SPSS software. ${ }^{*} p<0.05,{ }^{* *} p<0.01$.

\section{Discussion}

In this study, we successfully identified 50 host-responsive DEPs via MALDI-TOF/TOF-MS in the hemolymph of female silkworm pupae after E. sorbillans infection. Parasitoids induce host responses such as enhancing innate immunity proteins expression and cell apoptosis.

\subsection{Innate Immune System Enhanced Resistance to E. sorbillans Infestation}

Parasitoids induce host responses. In particular, the following eight innate immune proteins were successfully identified and upregulated in the infected group: PPO2 (spot 1), paralytic peptide binding protein (spot 4) [22,23], antitrypsin (spot 6) [24], CTL10 (spot 10), apolipophorin III (spot 22) [25], translationally controlled tumor protein (spot 23) [26,27], peptidoglycan recognition protein (spot 27) [28,29], and ubiquitin-like protein SMT3 (spot 36) [30,31]. Three proteins, PPO2, antitrypsin, and paralytic peptide binding protein, were identified as an immune adaptation against $E$. bombycis parasites in B. mori by Pradeep et al [8]. They all play important roles in innate immunity. Insect prophenoloxidase (PPO) is an important innate immunity protein [32]. The activation of PPO cleaving into active phenoloxidase $(\mathrm{PO})$ by serine proteinase is required for a melanization cascade to isolate microorganisms from circulation and to then kill them [33]. Produced by hindgut cells, PPO is secreted into the hindgut content that induces the melanization of the hindgut content in silkworm [34]. BmCTL10 and BmMBP are the same C-type lectins (CTLs), and their amino acid sequence similarity is $99.7 \%$; they participate in innate immune responses such as hemocyte nodule formation and PPO activation [4,35-37]. As a result of activation of the PPO cascade and nodule formation, the parasite is blackened in the host by the deposition of melanin and encapsulation. This indicates that the expressions of immune proteins are enhanced in the silkworm resistance of E. sorbillans parasite infestation.

\subsection{Apoptosis Triggered in Response to E. sorbillans Infestation}

Parasitic infection induces autophagy and cell apoptosis in insects [6]. Cathepsin B and 14-3-3 zeta both have important roles in apoptosis $[38,39]$. RNAi-mediated downregulation of cathepsin B or the absence of cathepsin B induces apoptosis in cancer [38,40,41]. Downregulation of cathepsin B can induce caspase-8-mediated apoptosis and initiates a partial extrinsic apoptotic cascade in SNB19 human glioma cells [40]. Strong 14-3-3 zeta protein expression acts in cell differentiation, proliferation, transformation, and prevention of apoptosis [42]. In particular, 14-3-3 protein zeta is a major regulator of apoptotic pathways in insects and vertebrates [43-46]; downregulation of 14-3-3 zeta sensitizes cells to apoptosis $[39,47]$. Cathepsin B (spots 43) and 14-3-3 zeta (spot 45) were successfully identified and were significantly downregulated in the hemolymph of parasitized female silkworm pupae. Cathepsin B was transcriptionally downregulated in the host Manduca sexta following wasp Cotesia congregata parasitism [48]. The downregulation of cathepsin B and 14-3-3 zeta may induce cell apoptosis in the 
hemolymph of B. mori following the invasion by the E. sorbillans. The larval epithelium of B. mori parasitized by E. bombycis showed cellular responses, such as signs of autophagy and apoptosis [8]. Enhanced expression of autophagy 5-like (Atg5), apoptosis-inducing Factor (AIF), and caspase genes coupled with the appearance of cell death symptoms indicate parasitism-induced activation of genetic machinery to modulate cell apoptosis in the epithelium [12]. Thus, cell apoptosis is triggered against the parasitism of E. sorbillans in B. mori.

Proteins related to growth and development, such as the ecdysteroid-regulated $16 \mathrm{kDa}$ protein, were successfully identified. Ecdysteroid-regulated $16 \mathrm{kDa}$ protein (ESR16) is triggered by the steroid hormone ecdysone at the onset of metamorphosis [49]. The developmentally regulated gene of ecdysteroid-regulated $16 \mathrm{kDa}$ protein was downregulated in the hemolymph of B. mori after E. sorbillans infection, which indicates that the development of the host is affected to facilitate the growth of parasitic larvae of the E. sorbillans maggot.

\section{Conclusions}

In conclusion, we successfully identified 50 differentially expressed proteins (DEPs) in the hemolymph of the day- 1 female silkworm pupae and their potential roles following silkworm maggot (Exorista sorbillans) parasitism using a proteomics-based approach. The expressions of immune proteins were enhanced, and cell apoptosis could be triggered against the parasitism of E. sorbillans in B. mori. To the best of our knowledge, this study is the first to report the identification of possible proteins from the E. bombycis-parasitized silkworms at the late stage of parasitism. Our findings expand the current knowledge on resistance in silkworm to E. sorbillans parasitization and provide a new perspective on the molecular mechanisms of dipteran parasitoid biology.

Supplementary Materials: The following are available online at http://www.mdpi.com/2075-4450/10/11/413/s1. Figure S1. Tissue expression profile of genes encoding the differentially expressed proteins (DEPs). The columns represent 10 different tissues and both sexes: testis, ovary, head, epidermis, fat body, midgut, hemocyte, Malpighian tubule, anterior/median silk gland (A/MSG), and posterior silk gland (PSG) and female (F) and male (M). Gene expression levels are represented by red (higher expression) and blue (lower expression) boxes. Table S1. Peptides of the quantified proteins. Table S2. Gene Ontology (GO) annotation results of the DEPs. Table S3. Description of the Kyoto Encyclopedia of Genes and Genomes (KEGG) pathway. Table S4. Primers of genes for quantitative PCR (qPCR).

Author Contributions: A.-Y.X. designed the study. P.-Z.X. drafted the manuscript. M.-R.Z. and L.G. performed the experiments. Y.-C.W., H.-Y.Q., and G.L. analyzed the data. All authors read and approved the final version of the manuscript.

Funding: This work was financially supported by the Natural Science Foundation of Jiangsu Province (grant no. BK2012273) and the National Natural Science Foundation of China (grant no. 31302035).

Conflicts of Interest: None of the authors have any actual or potential conflicts of interest.

\section{References}

1. Hoffmann, J.A.; Kafatos, F.C.; Janeway, C.A.; Ezekowitz, R.A. Phylogenetic perspectives in innate immunity. Science 1999, 284, 1313-1318. [CrossRef] [PubMed]

2. Hoffmann, J.A. The immune response of Drosophila. Nature 2003, 426, 33-38. [CrossRef] [PubMed]

3. Osta, M.A.; Christophides, G.K.; Vlachou, D.; Kafatos, F.C. Innate immunity in the malaria vector Anopheles gambiae: Comparative and functional genomics. J. Exp. Biol. 2004, 207, 2551-2563. [CrossRef] [PubMed]

4. Tanaka, H.; Ishibashi, J.; Fujita, K.; Nakajima, Y.; Sagisaka, A.; Tomimoto, K.; Suzuki, N.; Yoshiyama, M.; Kaneko, Y.; Iwasaki, T.; et al. A genome-wide analysis of genes and gene families involved in innate immunity of Bombyx mori. Insect Biochem. Mol. Biol. 2008, 38, 1087-1110. [CrossRef] [PubMed]

5. Yadav, S.; Eleftherianos, I. Prolonged Storage Increases Virulence of Steinernema Entomopathogenic Nematodes Toward Drosophila Larvae. J. Parasitol. 2018, 104, 722-725. [CrossRef] [PubMed]

6. Filosa, J.N.; Berry, C.T.; Ruthel, G.; Beverley, S.M.; Warren, W.C.; Tomlinson, C.; Myler, P.J.; Dudkin, E.A.; Povelones, M.L.; Povelones, M. Dramatic changes in gene expression in different forms of Crithidia fasciculata reveal potential mechanisms for insect-specific adhesion in kinetoplastid parasites. PLoS Negl. Trop. Dis. 2019, 13, e0007570. [CrossRef] 
7. Wang, J.; Xia, Q.; He, X.; Dai, M.; Ruan, J.; Chen, J.; Yu, G.; Yuan, H.; Hu, Y.; Li, R.; et al. SilkDB: A knowledgebase for silkworm biology and genomics. Nucleic Acids Res. 2005, 33, D399-D402. [CrossRef]

8. Pradeep, A.N.; Anitha, J.; Awasthi, A.K.; Babu, M.A.; Geetha, M.N.; Arun, H.K.; Chandrashekhar, S.; Rao, G.C.; Vijayaprakash, N.B. Activation of autophagic programmed cell death and innate immune gene expression reveals immuno-competence of integumental epithelium in Bombyx mori infected by a dipteran parasitoid. Cell Tissue Res. 2013, 352, 371-385. [CrossRef]

9. Jayaram, A.; Pradeep, A.N.R.; Awasthi, A.K.; Murthy, G.N.; Ponnuvel, K.M.; Sasibhushan, S.; Rao, G.C. Coregulation of host-response genes in integument: Switchover of gene expression correlation pattern and impaired immune responses induced by dipteran parasite infection in the silkworm, Bombyx mori. J. Appl. Genet. 2014, 55, 209-221. [CrossRef]

10. Pooja, M.; Pradeep, A.N.R.; Hungund, S.P.; Sagar, C.; Ponnuvel, K.M.; Awasthi, A.K.; Trivedy, K. Oxidative stress and cytotoxicity elicited lipid peroxidation in hemocytes of Bombyx mori larva infested with dipteran parasitoid, Exorista bombycis. Acta Parasitol. 2017, 62, 717-727. [CrossRef]

11. Makwana, P.; Pradeep, A.N.; Hungund, S.P.; Ponnuvel, K.M.; Trivedy, K. The dipteran parasitoid Exorista bombycis induces pro- and anti-oxidative reactions in the silkworm Bombyx mori: Enzymatic and genetic analysis. Arch. Insect Biochem. Physiol. 2017, 94. [CrossRef]

12. Anitha, J.; Pradeep, A.R.; Sivaprasad, V. Upregulation of Atg5 and AIF gene expression in synchronization with programmed cellular death events in integumental epithelium of Bombyx mori induced by a dipteran parasitoid infection. Bull. Entomol. Res. 2014, 104, 794-800. [CrossRef] [PubMed]

13. Shiba, H.; Uchida, D.; Kobayashi, H.; Natori, M. Involvement of cathepsin B- and L-like proteinases in silk gland histolysis during metamorphosis of Bombyx mori. Arch. Biochem. Biophys. 2001, 390, 28-34. [CrossRef] [PubMed]

14. Kumar, A.; Srivastava, P.; Sirisena, P.; Dubey, S.K.; Kumar, R.; Shrinet, J.; Sunil, S. Mosquito Innate Immunity. Insects 2018, 9. [CrossRef]

15. Shevchenko, A.; Wilm, M.; Vorm, O.; Mann, M. Mass spectrometric sequencing of proteins silver-stained polyacrylamide gels. Anal. Chem. 1996, 68, 850-858. [CrossRef]

16. Wang, X.Y.; Yu, H.Z.; Xu, J.P.; Zhang, S.Z.; Yu, D.; Liu, M.H.; Wang, L.L. Comparative Subcellular Proteomics Analysis of Susceptible and Near-isogenic Resistant Bombyx mori (Lepidoptera) Larval Midgut Response to BmNPV infection. Sci. Rep. 2017, 7, 45690. [CrossRef]

17. Quevillon, E.; Silventoinen, V.; Pillai, S.; Harte, N.; Mulder, N.; Apweiler, R.; Lopez, R. InterProScan: Protein domains identifier. Nucleic Acids Res. 2005, 33, W116-W120. [CrossRef]

18. Gotz, S.; Garcia-Gomez, J.M.; Terol, J.; Williams, T.D.; Nagaraj, S.H.; Nueda, M.J.; Robles, M.; Talon, M.; Dopazo, J.; Conesa, A. High-throughput functional annotation and data mining with the Blast2GO suite. Nucleic Acids Res. 2008, 36, 3420-3435. [CrossRef]

19. Kanehisa, M.; Goto, S.; Sato, Y.; Furumichi, M.; Tanabe, M. KEGG for integration and interpretation of large-scale molecular data sets. Nucleic Acids Res. 2012, 40, D109-D114. [CrossRef]

20. Zhang, M.; Qin, S.; Xu, P.; Zhang, G. Identifying potential maternal genes of Bombyx mori using digital gene expression profiling. PLoS ONE 2018, 13, e0192745. [CrossRef]

21. Zhao, P.; Dong, Z.; Duan, J.; Wang, G.; Wang, L.; Li, Y.; Xiang, Z.; Xia, Q. Genome-wide identification and immune response analysis of serine protease inhibitor genes in the silkworm, Bombyx mori. PLoS ONE 2012, 7, e31168. [CrossRef] [PubMed]

22. Nakahara, Y.; Kanamori, Y.; Kiuchi, M.; Kamimura, M. Effects of silkworm paralytic peptide on in vitro hematopoiesis and plasmatocyte spreading. Arch. Insect Biochem. Physiol. 2003, 52, 163-174. [CrossRef] [PubMed]

23. Hu, Z.G.; Chen, K.P.; Yao, Q.; Gao, G.T.; Xu, J.P.; Chen, H.Q. Cloning and characterization of Bombyx mori PP-BP a gene induced by viral infection. Yi Chuan Xue Bao Acta Genet. Sin. 2006, 33, 975-983. [CrossRef]

24. Liu, H.F.; Li, Y.N.; Jia, R.; Cui, W.Z.; Mu, Z.M.; Zhang, Z.F. Alternative splicing of the antitrypsin gene in the silkworm, Bombyx mori. Mol. Biol. Rep. 2011, 38, 2793-2799. [CrossRef] [PubMed]

25. Wen, D.; Wang, X.; Shang, L.; Huang, Y.; Li, T.; Wu, C.; Zhang, R.; Zhang, J. Involvement of a versatile pattern recognition receptor, apolipophorin-III in prophenoloxidase activation and antibacterial defense of the Chinese oak silkworm, Antheraea pernyi. Dev. Comp. Immunol. 2016, 65, 124-131. [CrossRef] [PubMed] 
26. Lee, J.M.; Kusakabe, T.; Kawaguchi, Y.; Miyagawa, Y.; Takahashi, M.; Mon, H.; Nho, S.K.; Koga, K. Molecular cloning and characterization of the translationally controlled tumor protein gene in Bombyx mori. Comp. Biochem. Physiol. Part B Biochem. Mol. Biol. 2004, 139, 35-43. [CrossRef]

27. Wang, F.; Hu, C.; Hua, X.; Song, L.; Xia, Q. Translationally controlled tumor protein, a dual functional protein involved in the immune response of the silkworm, Bombyx mori. PLoS ONE 2013, 8, e69284. [CrossRef]

28. Werner, T.; Liu, G.; Kang, D.; Ekengren, S.; Steiner, H.; Hultmark, D. A family of peptidoglycan recognition proteins in the fruit fly Drosophila melanogaster. Proc. Natl. Acad. Sci. USA 2000, 97, 13772-13777. [CrossRef]

29. Royet, J.; Reichhart, J.M.; Hoffmann, J.A. Sensing and signaling during infection in Drosophila. Curr. Opin. Immunol. 2005, 17, 11-17. [CrossRef]

30. Muller, S.; Hoege, C.; Pyrowolakis, G.; Jentsch, S. SUMO, ubiquitin's mysterious cousin. Nat. Rev. Mol. Cell Biol. 2001, 2, 202-210. [CrossRef]

31. Xu, H.P.; Hao, W.; He, D.; Xu, Y.S. Smt3 is required for the immune response of silkworm, Bombyx mori. Biochimie 2010, 92, 1306-1314. [CrossRef] [PubMed]

32. Lemaitre, B.; Hoffmann, J. The host defense of Drosophila melanogaster. Ann. Rev. Immunol. 2007, 25, 697-743. [CrossRef] [PubMed]

33. De Gregorio, E.; Han, S.J.; Lee, W.J.; Baek, M.J.; Osaki, T.; Kawabata, S.; Lee, B.L.; Iwanaga, S.; Lemaitre, B.; Brey, P.T. An immune-responsive Serpin regulates the melanization cascade in Drosophila. Dev. Cell 2002, 3, 581-592. [CrossRef]

34. Shao, Q.M.; Yang, B.; Xu, Q.Y.; Li, X.Q.; Lu, Z.Q.; Wang, C.S.; Huang, Y.P.; Soderhall, K.; Ling, E.J. Hindgut Innate Immunity and Regulation of Fecal Microbiota through Melanization in Insects. J. Biol. Chem. 2012, 287, 14270-14279. [CrossRef] [PubMed]

35. Koizumi, N.; Imamura, M.; Kadotani, T.; Yaoi, K.; Iwahana, H.; Sato, R. The lipopolysaccharide-binding protein participating in hemocyte nodule formation in the silkworm Bombyx mori is a novel member of the C-type lectin superfamily with two different tandem carbohydrate-recognition domains. FEBS Lett. 1999, 443, 139-143. [CrossRef]

36. Yu, X.Q.; Kanost, M.R. Immulectin-2, a lipopolysaccharide-specific lectin from an insect, Manduca sexta, is induced in response to gram-negative bacteria. J. Biol. Chem. 2000, 275, 37373-37381. [CrossRef] [PubMed]

37. Watanabe, A.; Miyazawa, S.; Kitami, M.; Tabunoki, H.; Ueda, K.; Sato, R. Characterization of a novel C-type lectin, Bombyx mori multibinding protein, from the B. mori hemolymph: Mechanism of wide-range microorganism recognition and role in immunity. J. Immunol. 2006, 177, 4594-4604. [CrossRef]

38. Gondi, C.S.; Kandhukuri, N.; Kondraganti, S.; Gujrati, M.; Olivero, W.C.; Dinh, D.H.; Rao, J.S. RNA interference-mediated simultaneous down-regulation of urokinase-type plasminogen activator receptor and cathepsin B induces caspase-8-mediated apoptosis in SNB19 human glioma cells. Mol. Cancer 2006, 5, 3197-3208. [CrossRef]

39. Hashemi, M.; Zali, A.; Hashemi, J.; Oraee-Yazdani, S.; Akbari, A. Down-regulation of 14-3-3 zeta sensitizes human glioblastoma cells to apoptosis induction. Apoptosis 2018, 23, 616-625. [CrossRef]

40. Nagakannan, P.; Eftekharpour, E. Differential redox sensitivity of cathepsin B and L holds the key to autophagy-apoptosis interplay after Thioredoxin reductase inhibition in nutritionally stressed SH-SY5Y cells. Free Radic. Biol. Med. 2017, 108, 819-831. [CrossRef]

41. Yang, K.M.; Bae, E.; Ahn, S.G.; Pang, K.; Park, Y.; Park, J.; Lee, J.; Ooshima, A.; Park, B.; Kim, J.; et al. Co-chaperone BAG2 Determines the Pro-oncogenic Role of Cathepsin B in Triple-Negative Breast Cancer Cells. Cell Rep. 2017, 21, 2952-2964. [CrossRef] [PubMed]

42. Mackintosh, C. Dynamic interactions between 14-3-3 proteins and phosphoproteins regulate diverse cellular processes. Biochem. J. 2004, 381, 329-342. [CrossRef] [PubMed]

43. Ulvila, J.; Vanha-aho, L.M.; Kleino, A.; Vaha-Makila, M.; Vuoksio, M.; Eskelinen, S.; Hultmark, D.; Kocks, C.; Hallman, M.; Parikka, M.; et al. Cofilin regulator 14-3-3zeta is an evolutionarily conserved protein required for phagocytosis and microbial resistance. J. Leukoc. Biol. 2011, 89, 649-659. [CrossRef] [PubMed]

44. Lee, J.J.; Lee, J.S.; Cui, M.N.; Yun, H.H.; Kim, H.Y.; Lee, S.H.; Lee, J.H. BIS targeting induces cellular senescence through the regulation of 14-3-3 zeta/STAT3/SKP2/p27 in glioblastoma cells. Cell Death Dis. 2014, 5, e1537. [CrossRef] 
45. Weerasekara, V.K.; Panek, D.J.; Broadbent, D.G.; Mortenson, J.B.; Mathis, A.D.; Logan, G.N.; Prince, J.T.; Thomson, D.M.; Thompson, J.W.; Andersen, J.L. Metabolic-stress-induced rearrangement of the 14-3-3zeta interactome promotes autophagy via a ULK1- and AMPK-regulated 14-3-3zeta interaction with phosphorylated Atg9. Mol. Cell Biol. 2014, 34, 4379-4388. [CrossRef]

46. Trujillo-Ocampo, A.; Cazares-Raga, F.E.; Del Angel, R.M.; Medina-Ramirez, F.; Santos-Argumedo, L.; Rodriguez, M.H.; Hernandez-Hernandez, F.C. Participation of 14-3-3epsilon and 14-3-3zeta proteins in the phagocytosis, component of cellular immune response, in Aedes mosquito cell lines. Parasites Vectors 2017, 10, 362. [CrossRef]

47. Niemantsverdriet, M.; Wagner, K.; Visser, M.; Backendorf, C. Cellular functions of 14-3-3 zeta in apoptosis and cell adhesion emphasize its oncogenic character. Oncogene 2008, 27, 1315-1319. [CrossRef]

48. Serbielle, C.; Moreau, S.; Veillard, F.; Voldoire, E.; Bezier, A.; Mannucci, M.A.; Volkoff, A.N.; Drezen, J.M.; Lalmanach, G.; Huguet, E. Identification of parasite-responsive cysteine proteases in Manduca sexta. Biol. Chem. 2009, 390, 493-502. [CrossRef]

49. Li, Y.D.; Hui, M.; Cui, Z.X.; Liu, Y.; Song, C.W.; Shi, G.H. Comparative transcriptomic analysis provides insights into the molecular basis of the metamorphosis and nutrition metabolism change from zoeae to megalopae in Eriocheir sinensis. Comp. Biochem. Phys. D 2015, 13, 1-9. [CrossRef]

(C) 2019 by the authors. Licensee MDPI, Basel, Switzerland. This article is an open access article distributed under the terms and conditions of the Creative Commons Attribution (CC BY) license (http://creativecommons.org/licenses/by/4.0/). 